\title{
Does Spatial Heterogeneity Matter in the EU Regions' Convergence Income Process? ${ }^{1}$
}

\author{
Andrea FURKOVÁ*
}

\begin{abstract}
This paper explores the role spatial heterogeneity in the EU regions' convergence income process. For this purpose we tested income convergence hypothesis of the 245 NUTS 2 European Union regions during the period 2003 - 2014. We used spatial econometric approach which allowed an explicit modelling of both spatial effects: spatial heterogeneity and spatial autocorrelation. Our results showed an appropriate consideration of the role of spatial effects. First, we found that the rate of economic growth in the region is not only affected by the exogenous characteristics of the region, but also potentially by the rate of economic growth in neighbouring regions. Secondly, estimated spatial regime model identified two spatial regimes - convergence clubs. The regions under the first spatial convergence regime included economically „weaker” regions (mainly regions of post-socialist countries, regions of Portugal, Spain, Greece and southern regions of Italy) and these regions are converging separately from the rest of regions of the $E U$.
\end{abstract}

Keywords: club income convergence, spatial heterogeneity, spatial econometric models, NUTS 2 regions

JEL Classification: C21, R11

DOI: https://doi.org/10.31577/ekoncas.2020.07.02

\section{Introduction}

In last decades, the issue of income convergence in the EU countries and regions is considered as an important area of research for analysts as well as for economic policy makers. This growing interest is mainly due to the process of EU

\footnotetext{
* Andrea FURKOVÁ (ORCID 0000-0002-8344-7806), University of Economics in Bratislava, Faculty of Economic Informatics, Department of Operations Research and Econometrics, Dolnozemská cesta 1, 85235 Bratislava, Slovak Republic; e-mail: andrea.furkova@euba.sk

${ }^{1}$ This work was supported by the Grant Agency of Slovak Republic - VEGA 1/0193/20 Impact of Spatial Spillover Effects on Innovation Activities and Development of EU Regions.
} 
enlargement, which is accompanied by the problems of regional differences and convergence. Also, balanced regional development and the reduction of regional disparities is one of the EU's main objectives (European Commission, 2012).

In terms of economic growth theory, the Solow neoclassical economic growth model is generally considered to be the basic model of convergence analysis (Solow, 1956). This model is based on the assumption that the output of each country converges to the steady state given by the economic conditions. The theory of endogenous growth, based on Romer (1986), argues that homogeneous groups of countries tend to converge and heterogeneously diverge. Among the most cited studies in the area of convergence analysis are the work of NEG (New Economic Geography) authors, Krugman (1991) or Barro and Sala-i-Martin (1991). Their research was mainly aimed at the regional convergence and the „region“ was considered as a meaningful observation unit in relation to spatial economic analysis.

Empirical literature includes many studies dealing with regional income convergence, but the common feature of most „earlier“ studies in this area is the neglected aspect of spatial interactions between the units under observation. It is generally recognized that regions with high economic growth performance are geographically distant from regions with slow economic growth. The problem of possible biased results and consequently misleading conclusions from empirical studies, which did not take into account the influence of the region's location in the growth process, was pointed out in Carrington (2003), Fingleton and López-Bazo (2006) and Paas et al. (2007). The work of Abreu and De Groot (2005) provides an overview of methods and empirical studies of economic growth and income convergence, emphasizing the importance of spatial factors. One of the first studies where the existence of spatial effects in income regional convergence was taken into account was the study of Rey and Montouri (1999). They analysed income convergence of the US regions. From the studies that dealt with the analysis of income convergence in the EU context based on spatial econometrics tools, can be mentioned, e.g., Carrington (2003), Arbia (2006), Feldkircher (2006), Paas and Schlitte (2009), Battisti and Di Vaio (2009) or Baumont, Ertur and Le Gallo (2001). For instance Baumont, Ertur and Le Gallo (2001) study of the 138 European regions surveyed between 1980 and 1995 confirmed the existence of spatial effects, namely that the average regional GDP growth rate per capita is influenced by the average growth rate in neighbouring regions.

Three convergence hypotheses are known in the literature of economic growth and regional convergence Galor (1996): absolute (unconditional) convergence, conditional convergence, and club convergence. The theoretical aspects and definitions of convergence hypotheses are well known and are the subject of 
many professional works (see, e.g., Battisti and Di Vaio, 2009; Hančlová et al., 2010). In the context of empirical testing of convergence hypotheses, especially beta-convergence approach is applied. From this point of view (see, e.g., Barro and Sala-i-Martin, 1990; 1991; 1992; Galor, 1996) the hypothesis is that poorer economies" per capita incomes will tend to grow at faster rates than richer economies. This concept will also be a starting point for convergence analysis of our work, but we will focus on club convergence in the context of spatial effects.

According to the classic definition of club convergence (Barro and Sala-i-Martin, 1991), it means that a group of regions that have the same initial and structural characteristics will approach the same equilibrium. The concept of traditional club convergence is already relatively widely applied in the context of regional economic growth analysis (e.g. Paas et al., 2007; Mora, 2005) but spatial dimension extension is very rare.

The traditional concept of club convergence is subject of criticism due to the ignorance of the spatial correlation of regional economic growth and the fact that regions are perceived as ,islands“ in the economic space. So the phenomenon of spatial autocorrelation is not taken into account in the traditional concept of club convergence. Another factor of criticism is the neglect of spatial heterogeneity and clustering. Dall'erba (2005) states that spatial heterogeneity means that economic behaviour is unstable in space, and club convergence is characterized by multiple local equilibrium states.

The existence of spatial club convergence necessarily involves a new concept called spatial club convergence. However, at present, we have very few literature where spatial club convergence has been accepted as a formal concept of regional convergence. Also, the definition of spatial club convergence is not clearly defined. In Qin, Ye and Liu (2017), Papalia and Betarelli (2012) and Pan, Liu and Peng (2015) a spatial club convergence is defined as the economic growth of a group of regions that are spatially ,adjacent" with the same initial conditions and structural characteristics to approach the same equilibrium state. The mechanism of the formation of the spatial convergence clubs has similar characteristics as the formation mechanism of the traditional convergence clubs, but it also has its own spatial aspects.

Economic theory does not provide guidance as to the number of convergence clubs or the way in which an explanatory variable defining initial conditions determines clubs (Durlauf and Johnson, 1995). Several approaches to the determination of convergence clubs have been proposed in the empirical literature. These approaches can be divided into two basic categories. Debarsy and Ertur (2006) distinguish between exogenous and endogenous methods for identifying convergence clubs. The first category includes approaches where the criteria for 
creating clubs are, e.g. affiliation to the geographical zone, the institutional system or Durlauf and Johnson (1995) identified clubs on the basis of selected per capita GDP levels. The second category of approaches also includes Exploratory Spatial Data Analysis (ESDA) tools. The ESDA applied to a variable that defines the starting conditions of the convergence process is a suitable tool for determining spatial regimes as it allows to detect spatial interactions between regions on the basis of baseline income regions.

It is assumed that spatial spillover effects will have a significant impact on spatial club convergence. Mechanisms by which spatial spillover effects affect the spatial convergence of club include several factors. Through spatial spillover effects, the rate of economic growth in the region is influenced by the rate of economic growth, economic levels and incidental shocks in neighbouring regions. Also, spatial spillover effects affect the economic structures of regions that tend to be similar due to factors such as, for example, raw materials, through competition and imitation between neighbouring regions. The influence of these factors is beneficial with respect to the formation of the same economic growth trajectory and convergence to the same equilibrium state.

As we have already mentioned, the concept of spatial club convergence is not fully established in professional literature, either in theoretical or empirical terms. The studies aimed at testing the hypothesis of spatial club convergence or the existence of multiple spatial convergence clubs can be found e.g., in the following studies: Ertur, Le Gallo and Baumont (2006) focused on the convergence process of the European regions between 1980 and 1995. The study confirmed the different convergence process in individual spatial regimes. Fischer and Stirböck (2004) analysed and confirmed the hypothesis of spatial club convergence of 256 regions of European countries in the period 1995 - 2000. Ramajo et al. (2005) examined the convergence rate of $163 \mathrm{EU}$ regions in the period 1981 - 1996. In this work, the authors identified two regimes (cohesive and noncohesive countries) and confirmed a faster income convergence of cohesion countries (5.3\%) than in other regions EU (3.3\%). Debarsy and Ertur (2006) examined the convergence processes related to the enlargement of the EU with the new Member States over the period 1993 - 2002 concerning the two clubs. Ramajo et al. (2008) applied spatial econometric methods to estimate the convergence rate of $163 \mathrm{EU}$ regions in the period 1981 - 1996 based on multiple spatial clubs. Qin et al. (2017) tested and verified the hypothesis of the spatial convergence of the Chinese urban agglomeration over the period $1993-2009$.

The empirical analysis presented in this paper will focus on testing the spatial income convergence hypothesis of the EU 245 NUTS 2 (Nomenclature of Units for Territorial Statistics) regions during the period $2003-2014$. The main motivation 
for this analysis is the fact that the classical concept of income convergence neglects spatial effects between regions what caused misleading results and conclusions.

As mentioned above, the basic methodological tool for analysis will be the beta-convergence concept, but the two main aspects will differentiate this analysis from most convergence analyses. The first aspect is that the spatial interactions and spillover effects between regions and their perceptions as a mechanism that can lead to convergence will be taken into account. The second aspect is the relaxation of the assumption of the existence of a single equilibrium state for all regions, instead of the existence of spatial convergence clubs (spatial convergence regimes) and the existence of spatial interactions between regions belonging to individual clubs.

The rest of the paper is organized as follows: section 1 deals with main theoretical issues concerning the spatial effects and spatial regimes, section 2 presents empirical results and the paper closes with concluding remarks.

\section{Spatial Effects}

Spatial effects contains two main categories, namely spatial autocorrelation and spatial heterogeneity. Spatial autocorrelation deals with spatial dependence which is usually related to the geographical location or distance between spatial units - locations (regions, countries, etc.). Spatial heterogeneity can be perceived as a special case of cross-sectional heterogeneity and we will pay it more attention in next parts of this section.

Spatial effects are subject of interest of spatial econometrics, however more attention is focused on the estimation of models with spatially autoregressive process, i.e., models that explicitly allow for spatial dependence through spatially lagged variables. The family of these models are based on the generalized version called General Nesting Spatial (GNS) model. The GNS model for cros-sectional data in matrix form can be expressed as:

$$
\begin{aligned}
& \mathbf{y}=\rho \mathbf{W y}+\mathbf{X} \boldsymbol{\beta}+\mathbf{W X} \boldsymbol{\gamma}+\mathbf{u} \\
& \mathbf{u}=\lambda \mathbf{W u}+\mathbf{v}, \quad \mathbf{v} \sim N\left(\mathbf{0}, \sigma_{v}^{2} \mathbf{I}_{N}\right)
\end{aligned}
$$

where $\mathbf{y}$ is $N \times 1$ vector of the observed dependent variable for all $N$ locations, $\mathbf{X}$ denotes a $N \times k$ matrix of exogenous explanatory variables ( $k$ represents the number of explanatory variables), $\boldsymbol{\beta}$ is associated $k \times 1$ vector of unknown parameters to be estimated, $\mathbf{v} \sim N\left(\mathbf{0}, \sigma_{v}^{2} \mathbf{I}_{N}\right)$ is $N \times 1$ vector of random errors, $\sigma_{v}^{2}$ is random error variance, $\mathbf{I}_{N}$ is $N$ dimensional unit matrix and $\mathbf{W}$ is $N$ dimensional 
spatial weighting matrix (for more details regarding spatial weighting matrices see, e.g. Anselin and Rey, 2014 or Chocholatá, 2018) We can see that model (1) includes all types of spatial interaction effects (endogenous interaction effects among the dependent variable $-\mathbf{W y}$, the exogenous interaction effects among the independent variables - $\mathbf{W X}$ and the interaction effects among the disturbance term of the different units $-\mathbf{W u}$ ) and $k \times 1$ vector $\boldsymbol{\gamma}$, parameters $\rho$ and $\lambda$ represent spatial autoregressive parameters.

For example, if we set in the model (1) $\lambda=0, \rho \neq 0, \gamma=\mathbf{0}$ and $\boldsymbol{\beta} \neq \mathbf{0}$ we obtain SAR (Spatial Autoregressive) model:

$$
\mathbf{y}=\rho \mathbf{W} \mathbf{y}+\mathbf{X} \boldsymbol{\beta}+\mathbf{u}, \quad \mathbf{u} \sim N\left(\mathbf{0}, \sigma^{2} \mathbf{I}\right)
$$

Review of other spatial econometric models and topics related to estimation procedures can be found in, e.g. Anselin and Rey (2014).

Spatial heterogeneity is associated with the situation where it is assumed that the relationship between the dependent variable and the explanatory variables may vary spatially. Consequently, instead of fixed values of regression parameters for all spatial units, it is assumed that their values may be different for spatial unit groups called spatial regimes. In the most general case, we may expect a different relationship to hold for every point in space. Formally, we can write a linear relationship depicting this as follows:

$$
y_{i}=\mathbf{x}_{i}^{\mathrm{T}} \boldsymbol{\beta}_{i}+u_{i}
$$

where $i$ indexes observations collected at $i=1,2, \ldots, N$ points in space (spatial units), $\mathbf{x}_{i}^{\mathrm{T}}$ represents a $1 \times k$ vector of explanatory variables with an associated set of $k \times 1$ parameters $\boldsymbol{\beta}_{i}, y_{i}$ is the dependent variable at observation $i$ and $u_{i}$ denotes a stochastic disturbance in the linear relationship.

A set of estimated local regression parameters can be obtained by Geographically Weighted Regression (GWR) method (see e.g., Brunsdon, Fotheringham and Charlton, 1999).

With respect to the goal of our analysis, GWR methodology will be not discussed here, the methodological issues related to the spatial regimes, i. e., situation when we assume different regression parameter values for groups of spatial units, will be briefly discussed in next section.

\subsection{Spatial Regimes}

The basic spatial regimes specification can be formulated as follows:

$$
y_{i j}=\alpha_{j}+\mathbf{x}_{i j}^{\mathrm{T}} \boldsymbol{\beta}_{j}+u_{i j}, \quad i=1,2, \ldots, N, j=1,2, \ldots, J
$$


where

$i$ - indexes observations,

$j$ - indexes spatial regimes,

$J$ - total number of spatial regimes.

Each regime $j$ has its own intercept $\alpha_{j}$ and set of parameters $\boldsymbol{\beta}_{j}$. The standard assumption is homoscedasticity, i.e. $\operatorname{var}\left[u_{i j}\right]=\sigma^{2}$, but more realistic is group wise heteroscedasticity, i.e. $\operatorname{var}\left[u_{i j}\right]=\sigma_{j}^{2}$ for each $j$.

Basically, if group wise heteroscedasticity is assumed, the specification of spatial regimes is equivalent to separate regressions for each group (regime) and we can use standard approaches to structural stability testing as in non-spatial regression models. A different set of parameters for each regime $j$ indicates that the response of the dependent variable to the explanatory variables is not homogeneous. To illustrate spatial regime model, let us consider a situation where structural instability concerns two sub regions, that is, a model with two spatial regimes. This model can be specify as:

$$
\left[\begin{array}{l}
\mathbf{y}_{1} \\
\mathbf{y}_{2}
\end{array}\right]=\left[\begin{array}{cc}
\mathbf{X}_{1} & \mathbf{0} \\
\mathbf{0} & \mathbf{X}_{2}
\end{array}\right]\left[\begin{array}{l}
\boldsymbol{\beta}_{1} \\
\boldsymbol{\beta}_{2}
\end{array}\right]+\left[\begin{array}{l}
\mathbf{u}_{1} \\
\mathbf{u}_{2}
\end{array}\right]
$$

where $\mathbf{y}_{1}$ vector of dimension $N_{1} \times 1$ and $\mathbf{y}_{2}$ vector of dimension $N_{2} \times 1$ represent vectors of observations on the dependent variable (with $N_{1}+N_{2}=N$ ). Matrices $\mathbf{X}_{1}$ a $\mathbf{X}_{2}$ are of dimensions $N_{1} \times k$ and $N_{2} \times k$ ( $k$-number of parameters to be estimated), respectively, $\boldsymbol{\beta}_{1}$ and $\boldsymbol{\beta}_{2}$ are dimensions of $k \times 1, \mathbf{u}_{1}$ and $\mathbf{u}_{2}$ are random errors vectors of dimensions $N_{1} \times 1$ and $N_{2} \times 1$ respectively.

As we have already mentioned, this model can be estimated either assuming group homoscedasticity that means we assume a constant variance in both sub regions under consideration, i.e. $\boldsymbol{\Sigma}=\sigma^{2} \mathbf{I}_{N}$ or group wise heteroscedasticity, that is, $\mathrm{E}\left[\mathbf{u}_{1} \mathbf{u}_{1}^{\mathrm{T}}\right]=\boldsymbol{\Sigma}_{1}=\sigma_{1}^{2} \mathbf{I}_{N_{1}}$ and $\mathrm{E}\left[\mathbf{u}_{2} \mathbf{u}_{2}^{\mathrm{T}}\right]=\boldsymbol{\Sigma}_{2}=\sigma_{2}^{2} \mathbf{I}_{N_{2}}$. Eventually, a completely heteroskedastic random error term when the $\boldsymbol{\Sigma}$ matrix is a diagonal matrix with elements $\sigma_{i}^{2}$ may be an assumption. Model defined in (5) can be estimated by standard methods such as OLS, two-stage least squares, or FGLS (Feasible Generalized Least Squares) in the case of heteroscedasticity (see Anselin and Rey, 2014).

The point of departure of spatial effects testing in spatial regime models is spatial weight matrix $\mathbf{W}$ construction. Usually weights called regime weights $\mathbf{W}_{\mathbf{R}}$ are used. The regime weights are a block diagonal subset of the overall weights matrix $\mathbf{W}$, such that there is no interaction between blocks. 
Our two-regime model defined in (5) did not take into account spatial effects in terms of the spatial autoregressive model specification. Model (5) can be modified by inclusion a spatial lag term and/or a spatial autoregressive error process. Let us consider a spatial lag specification (SAR model). First, we suppose a fixed spatial autoregressive parameter $\rho$ (associated with spatially lagged dependent variable $\mathbf{W y}$ ), then the regime model specification becomes:

$$
\left[\begin{array}{l}
\mathbf{y}_{1} \\
\mathbf{y}_{2}
\end{array}\right]=\rho \mathbf{W}\left[\begin{array}{l}
\mathbf{y}_{1} \\
\mathbf{y}_{2}
\end{array}\right]+\left[\begin{array}{cc}
\mathbf{X}_{1} & \mathbf{0} \\
\mathbf{0} & \mathbf{X}_{2}
\end{array}\right]\left[\begin{array}{l}
\boldsymbol{\beta}_{1} \\
\boldsymbol{\beta}_{2}
\end{array}\right]+\left[\begin{array}{l}
\mathbf{u}_{1} \\
\mathbf{u}_{2}
\end{array}\right]
$$

where spatially lag dependent variable is constructed based on the overall matrix $\mathbf{W}$ and the compete vector $\mathbf{y}$. The specification in (6) is appropriate when there is an assumption of single spatial process operates on the whole date set.

A more realistic assumption seems to be an assumption of different spatial processes. In this case it is assumed that spatial parameters vary across regimes. If we again consider spatial lag specification and our two-regime model, model (6) can becomes:

$$
\left[\begin{array}{l}
\mathbf{y}_{1} \\
\mathbf{y}_{2}
\end{array}\right]=\left[\begin{array}{cc}
\rho_{1} \mathbf{W}_{1} & \mathbf{0} \\
\mathbf{0} & \rho_{2} \mathbf{W}_{2}
\end{array}\right]\left[\begin{array}{l}
\mathbf{y}_{1} \\
\mathbf{y}_{2}
\end{array}\right]+\left[\begin{array}{cc}
\mathbf{X}_{1} & \mathbf{0} \\
\mathbf{0} & \mathbf{X}_{2}
\end{array}\right]\left[\begin{array}{l}
\boldsymbol{\beta}_{1} \\
\boldsymbol{\beta}_{2}
\end{array}\right]+\left[\begin{array}{l}
\mathbf{u}_{1} \\
\mathbf{u}_{2}
\end{array}\right]
$$

where $\mathbf{W}_{1}$ and $\mathbf{W}_{2}$ are regime weights, $\rho_{1}$ and $\rho_{2}$ are spatial autoregressive parameters or particular regimes.

The model (5) can be extended to other specifications with spatial autoregressive terms, e.g. SEM - Spatial Error Model (Anselin, 1988; LeSage and Pace, 2009), SARAR (Kelejian and Prucha, 1998), SDM - Spatial Durbin Model (Anselin, 1988), SDEM - Spatial Durbin Error Model (LeSage and Pace, 2009) or SLX model (Spatial Lag in X) (Gibbons and Overman, 2012). The estimators for the spatial lag and error specification are direct extensions of the non-regime models (for more details see, e.g. Anselin and Rey, 2014).

\subsection{Local Measures of Spatial Autocorrelation}

In this last subsection focused on methodological aspects, we will very briefly present Getis-Ord statistic as a tool for identifying spatial autocorrelation. We will use this statistic in the empirical part as a starting point for the identification of spatial regimes and the division of regions into individual spatial convergence regimes. Local indicators have been suggested to analyse local spatial patterns, they assess the spatial autocorrelation association of the particular unit with its neighbouring areal units. 
The local version of family Getis-Ord statistic, $G_{i}(d)$ allows to detect pockets of spatial association that may not be evident when using global statistics. The $G_{i}(d)$ statistic is calculated for each spatial unit in the data set and for the location $i$ is defined as follows:

$$
G_{i}(d)=\frac{\sum_{j=1}^{N} w_{i j} x_{j}}{\sum_{j=1}^{N} x_{j}}, \quad j \neq i
$$

where $x_{j}$ represents the underlying variable value for region $j, N$ is the number of spatial units in the data set and $w_{i j}$ are the elements of spatial weighting matrix W. Local Getis-Ord statistic can be interpreted as a measure of local clustering of similar values around particular observation $i$ and positive values of statistic indicate clustering of high values (so called hot spots) and a negative values indicate a cluster of low values (so called cold spots). The testing of statistical significance of local measures of spatial autocorrelation follow similar idea as testing procedures of global measures (see e.g. Anselin and Rey, 2014).

\section{Empirical Analysis}

This section will focuses on testing the spatial income convergence hypothesis of the EU 245 NUTS 2 regions during the period 2003 - 2014. First, the data and spatial units used in our empirical analysis will be presented (subsection 2.1). Next, the spatial interactions and spillover effects between regions and their perceptions as a mechanism that can lead to convergence will be taken into account (subsection 2.2). In subsections 2.3 and 2.4, the assumption of the existence of a single equilibrium state for all regions will be relaxed and instead of that, the existence of spatial convergence clubs (spatial convergence regimes) will be verified.

\subsection{Data Description}

The analysis was based on the cross-sectional data obtained from the Eurostat regional statistics database (Eurostat, 2018a). Our dataset includes 245 NUTS 2 EU regions from 26 countries observed over the period $2003-2014$. As a regional income for individual regions, we chose GDP per capita in the Purchasing Power Parity (PPP) of NUTS 2 regions in logarithmic terms.

In econometric analysis we will use vector $\mathbf{y}$-observations of the dependent variable (GDP per capita growth in the period 2003 - 2014 in logarithmic form) 
and matrix $\mathbf{X}$ - matrix of observations of explanatory variable (GDP per capita in 2003 in logarithmic form and the first column of the matrix consists of units).

We have chosen an administrative regional structure at NUTS 2 level because this spatial division is defined by the European Commission to measure the level of convergence or divergence. At the beginning of the empirical analysis, from our data set we had to exclude the 20 island regions ${ }^{2}$ and 7 regions $^{3}$ due to missing data. The regions included in our analysis are shown in the form of box maps (see Figure 1).

Figure 1

Box Maps - GDP per capita in 2003 (left figure) and GDP per capita Growth Rate in Period 2003 - 2014 (right figure)

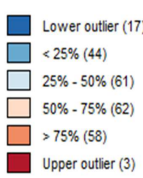

Upper outier (3)

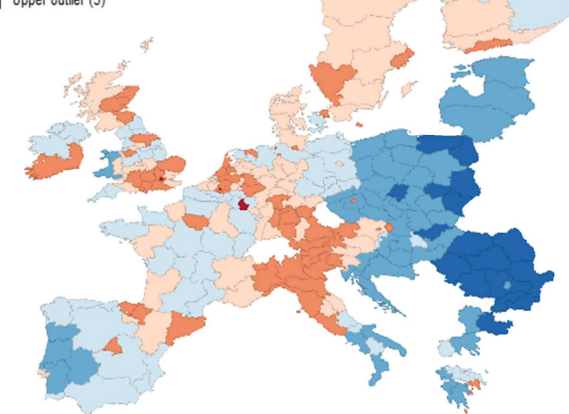

Source: Own elaboration in GeoDa. ${ }^{4}$

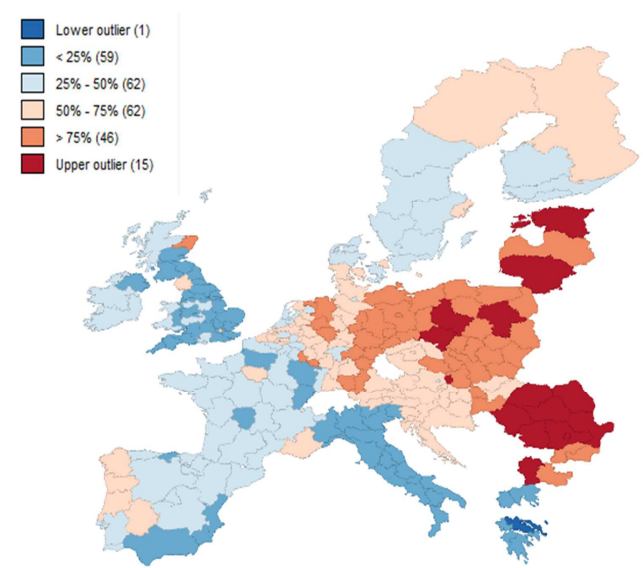

Figure 1 presents the box map for GDP per capita in 2003 (explanatory variable), which is our baseline period, and we can notice up to 17 outliers in the first quartile consisting mainly of the regions of Romania and Poland. Low GDP per capita values in 2003 are detected especially for the regions of post-socialist countries and the regions of Greece, Spain, Portugal and Italy. On the contrary, three extreme values in the fourth quartile correspond to the regions of Luxembourg, Belgium and the United Kingdom. The right side of the Figure 1 shows the map for growth of the GDP per capita in the period 2003 - 2014 (dependent variable). If we compare two box maps depicted in Figure 1, we can note the fact that most of regions with low GDP per capita values in the baseline period

\footnotetext{
${ }^{2}$ Regions of Cyprus, Malta, France, Finland, Spain, Greece, Portugal and Italy.

${ }^{3}$ Regions of Bulgaria, Germany and Greece.

${ }^{4}$ The whole empirical part of the paper was carried out in GeoDa and GeoDa Space softwares.
} 
correspond to regions with the highest GDP growth rates. This suggest a negative relationship between GDP per capita growth rates and GDP per capita in the baseline period.

Spatial units considered in our analysis are the EU regions at the NUTS 2 level. The geographical characteristics of these spatial units, in this case polygons, contain a .shp file obtained from Eurostat (Eurostat, 2018b). Exploratory Spatial Data Analysis (ESDA) as well as application of spatial econometric tools start by the decision about spatial weighting matrix $\mathbf{W}$. Throughout the analysis, we assumed that regions are "neighbours" if they share any part of the border and therefore queen contiguity weights were applied (for more details see e.g. Anselin and Rey, 2014).

In order to test the spatial effects in spatial regime models we had to construct a matrix of regime weights. This matrix has a block diagonal structure of weights and assuming two regimes, in our case two convergence clubs, this matrix has the following form:

$$
\mathbf{W}_{\mathbf{R}}=\left[\begin{array}{cc}
\mathbf{W}_{1} & \mathbf{0} \\
\mathbf{0} & \mathbf{W}_{2}
\end{array}\right]
$$

where $\mathbf{W}_{1}$ and $\mathbf{W}_{2}$ are truncated submatrices of the original matrix $\mathbf{W}$ (queen contiguity weights).

\subsection{Income Convergence of the EU Regions in the Context of Spatial Autocorrelation}

Adequate consideration of spatial effects in the convergence process of the EU regions involves a series of logical steps. The selected ESDA tools are usually the starting point of the analysis, which usually precede the tests of specification of spatial effects in the context of regression models, construction and estimation of spatial regression models. Our ESDA results ${ }^{5}$ indicated the spatial connectivity of regions in the GDP per capita growth process during the observed period. The next logical step is to specify a spatial econometric model that would take the spatial aspects into account. We chose a strategy called ,general to specific", where the model selection process begins with the construction and estimation of the model without spatially lagged variables and the OLS (Ordinary Least Squares) estimate. We start with the estimation of the following model of absolute beta convergence: ${ }^{6}$

\footnotetext{
${ }^{5}$ Due to insufficient space the results are not presented in the paper.

${ }^{6}$ Absolute as well as conditional beta-convergence issues are well known (e.g., see Mankiw, Romer and Weil, 1992 or Barro and Sala-i-Martin, 2004) and therefore we present only the necessary theoretical starting points.
} 


$$
\mathbf{y}=\mathbf{X} \gamma+\mathbf{u} \quad \mathbf{u} \sim N\left(\mathbf{0}, \sigma^{2} \mathbf{I}_{N}\right)
$$

where $\mathbf{y}$ vector of $N \times 1$ dimension is a vector of observations of the dependent variable (GDP per capita growth in the period 2003 - 2014 in logarithmic form), the parameter vector $\gamma$ dimension of $(2 \times 1)$ contains a parameter $\alpha$ (intercept) and a parameter $\beta$ corresponding to the explanatory variable (GDP per capita in 2003 in logarithmic form), $\mathbf{X}$ is a $N \times 2$ matrix of observations of explanatory variable (the first column of the matrix consists of units) and $\mathbf{u}$ is random errors vector of dimension $N \times 1$.

Model (10) is estimated by the OLS, including all 245 regions, i.e. we do not consider the existence of spatial convergence regimes. Next, we decide on the form of a proper spatial econometric model based on spatial statistics. The estimation results of the model (10) - SAR model are shown in Table 1.

T a b l e 1

\section{Estimation Results - OLS Model and SAR Model}

\begin{tabular}{|c|c|c|}
\hline & OLS model & SAR model \\
\hline & OLS & SML \\
\hline $\begin{array}{l}\alpha \\
\beta \\
\rho\end{array}$ & $\begin{array}{r}2.7956 * * * \\
-0.2564 * * * \\
-\end{array}$ & $\begin{array}{r}0.6175 * * * \\
-0.0562 * * * \\
0.7598 * * *\end{array}$ \\
\hline \multicolumn{3}{|c|}{ Goodness of fit } \\
\hline $\begin{array}{l}\mathrm{R}^{2} \\
\text { pseudo } \mathrm{R}^{2} \\
\text { pseudo } \mathrm{R}^{2}(\mathrm{~S}) \\
\text { AIC } \\
S C \\
\ln L \\
\text { Jarque-Bera } \\
\text { Breusch-Pagan }\end{array}$ & $\begin{array}{c}0.3952 \\
- \\
- \\
-257.546 \\
-250.543 \\
- \\
20.486 * * * \\
1.983 \\
\end{array}$ & $\begin{array}{c}- \\
0.7829 \\
0.5484 \\
-448.875 \\
-438.371 \\
227.438 \\
- \\
20.250 * * * \\
\end{array}$ \\
\hline \multicolumn{3}{|c|}{ Convergence characteristics } \\
\hline $\begin{array}{l}\text { Speed of convergence } \\
\text { Half life }\end{array}$ & $\begin{array}{l}2.69 \% \\
25.74 \\
\end{array}$ & $\begin{array}{r}0.53 \% \\
131.93 \\
\end{array}$ \\
\hline \multicolumn{3}{|c|}{ Statistics of spatial autocorrelation } \\
\hline Moran's I (residuals) & $10.639 * * *$ & - \\
\hline$L M(S A R)$ & $167.587 * * *$ & - \\
\hline Robust LM(SAR) & $67.947 * * *$ & - \\
\hline$L M(S E M)$ & $107.344 * * *$ & - \\
\hline Robust LM(SEM) & $7.704 * * *$ & - \\
\hline$L R$ & - & $193.330 * * *$ \\
\hline
\end{tabular}

Notes: Symbol *** indicates the rejection of $\mathrm{H}_{0}$ hypotheses at $1 \%$, level of significance. AIC - Akaike information criterion; $S C$ - Schwarz criterion; pseudo $\mathrm{R}^{2}(\mathrm{~S})$ - spatial pseudo $\mathrm{R}^{2}$; $\ln L$ - $\log$ arithm of $\log$ likelihood function; $L R$ - Likelihood Ratio; $L M$ - Lagrange Multiplier.

Source: Own calculations. 
The parameter $\beta$ of the OLS model (10) associated with the initial per capita GDP is significant and negative, which confirms the hypothesis of absolute income convergence for the NUTS 2 EU regions. This means that the regions with lower per capita GDP in the baseline period grew at a higher speed on average during the period 2003 - 2014. Based on parameter $\beta$ estimation, convergence characteristics such as a speed of convergence and a half life of convergence can be calculated (see e.g., see Arbia, 2006). The calculated convergence rate is $2.69 \%$ per year and the corresponding half life indicator is approximately 26 years (see Table 1). However, the statistical significance of Moran' $I$ (10.639***) applied to OLS residuals as well as $L M$ statistics (see Table 1) confirmed the presence of spatial dependencies of regions in the income convergence process and thus the results obtained by estimating the model (10) may be misleading. Since the results of the $L M$ test series did not allow a clear specification of the absolute beta-convergence spatial model, we decided to estimate several spatial versions of the model (10). ${ }^{7}$ The estimation of the SAR model is based on the following specification:

$$
\mathbf{y}=\rho \mathbf{W y}+\mathbf{X} \boldsymbol{\gamma}+\mathbf{u}
$$

All terms of the model (11) have been defined previously (see model (1), (2) and model (10)). We estimate the SAR model by using the Spatial Maximum Likelihood (SML) estimator, the results are given in Table 1. The estimation of the model (11), provided statistically significant estimates of all parameters with expected signs, but a very slow estimate of the convergence process of the NUTS 2 EU regions in the observed period was estimated (only $0.53 \%$ per year).

The first part of our empirical analysis was focused on explicit taking into account spatial interactions in the process of regional convergence. The estimation results of SAR model confirm the adequacy of this approach, i.e. statistically significant estimate of parameter $\rho$ which is associated with spatial lag of per capita GDP growth and the statistical significance of the spatial autoregressive parameter was also confirmed by the $L R$ test (see table $1-193.330^{* * *}$ ). It means, that changes in neighbouring location characteristics cause changes in the value of the dependent variable in particular region that will affect the value of the dependent variable in neighbouring units. These impacts are dispersed within the system of locations - the EU regions. Consequently, we can conclude that the GDP per capita growth in the particular region is influenced by GDP per capita growth values in neighbouring regions, i.e. there are significant spatial interactions in the process of regional EU convergence.

\footnotetext{
${ }^{7}$ Formulations as well as the results of all estimated spatial models for space reasons cannot be given and we are only focus on the resulting SAR model.
} 


\subsection{Income Club Convergence of the EU Regions}

The next part of the analysis will be devoted to testing the hypothesis of the existence of spatial convergence clubs - regimes, i.e. we will no longer assume one equilibrium state for all NUTS 2 EU regions but the existence of several steady equilibrium states for groups of regions that are spatially „close“ with the same initial conditions and structural characteristics. Different values of regression parameters between convergence clubs indicate different - heterogeneous reactions of GDP per capita growth to GDP per capita change in the baseline period. This hypothesis about spatial heterogeneity or spatial structural instability we will verify based on spatial regimes models. This topic was briefly discussed in section 1.1.

As we have already mentioned, the economic theory does not provide guidance as to the number of convergence clubs or the way in which an explanatory variable defining initial conditions determines clubs. We decided to use endogenous method for identifying convergence clubs - regimes based on the local Getis-Ord statistics as a tool of ESDA. Calculated $z$-values of local Getis-Ord statistics (regime variable) for GDP per capita in 2003 were the basis for the division of the NUTS 2 regions into two convergence regimes. Regime 1 consists of 79 regions and Regime 2 includes 166 regions. The assignment of the individual regions to the regimes is apparent from Figure 2. Our choice for 2 convergence clubs was influenced by our preliminary analysis as well as our own empirical analyses in previous publications (e.g. Furková and Chocholatá, 2016).

Figure 2

Natural Breaks Map (two categories: Orange Regions - Regime 1, Red Regions Regime 2, Break 0) For $\boldsymbol{Z}$ - Values of Local Getis-Ord Statistics for GDP per capita in 2003

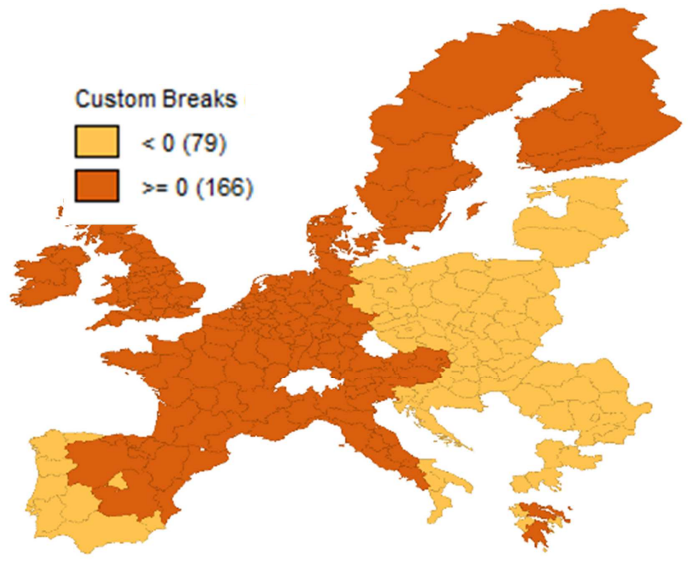

Source: Own elaboration in GeoDa. 
The basis for the analysis of two spatial convergence regimes is the following model (based on the model (5)):

$$
\left[\begin{array}{l}
\mathbf{y}_{1} \\
\mathbf{y}_{2}
\end{array}\right]=\left[\begin{array}{cc}
\mathbf{X}_{1} & \mathbf{0} \\
\mathbf{0} & \mathbf{X}_{2}
\end{array}\right]\left[\begin{array}{l}
\gamma_{1} \\
\gamma_{2}
\end{array}\right]+\left[\begin{array}{l}
\mathbf{u}_{1} \\
\mathbf{u}_{2}
\end{array}\right]
$$

where vectors $\mathbf{y}_{1}$ and $\mathbf{y}_{2}$ dimensions of $\left(N_{1} \times 1\right)$ and $\left(N_{2} \times 1\right)$ respectively, are subvectors of vector $\mathbf{y},\left(N_{1} \times 2\right)$ dimensional matrix $\mathbf{X}_{1}$ and $\left(N_{2} \times 2\right)$ dimensional matrix $\mathbf{X}_{2}$ are submatrices of matrix $\mathbf{X}, \boldsymbol{\gamma}_{1}, \boldsymbol{\gamma}_{2}$ are corresponding $(2 \times 1)$ vectors of parameters, vector $\mathbf{u}_{1}\left(N_{1} \times 1\right)$, vector $\mathbf{u}_{2}\left(N_{2} \times 1\right)$ are subvectors of vector $\mathbf{u}$ and vector $\mathbf{y}$, matrix $\mathbf{X}$ and vector $\mathbf{u}$ were defined before. Subscript denotes spatial regime, $N_{1}=79, N_{2}=166$, where $N_{1}+N_{2}=N$.

The model (12) will be estimated based on the FGLS estimator assuming the group wise heteroscedasticity - GHET (see section 2.1 or for more details Anselin and Rey, 2014). For verification purpose of the spatial homogeneity hypothesis, the Chow coefficient stability test will be used (for more details see Anselin and Rey, 2014). The results of the estimates are shown in Table 2. The regime weights matrix defined by formula (9) will be used within the estimates of all the following models.

Assuming group heteroscedasticity, the estimation of model (12) provides separate parameter estimates, separate goodness of fit statistics, convergence characteristics as well as individual spatial autocorrelation statistics for Regime 1 and Regime 2. We can see differences in estimated parameters as well as their statistical significance. The income convergence process of regions within Regime 1 has been confirmed and regions converge at 3.58\% per year. The regions under Regime 1 are economically ,weaker” regions, they are mainly regions of post-socialist countries, regions of Portugal, Spain, Greece and southern regions of Italy. On the other hand, the convergence process within the economically „stronger" regions of Regime 2 has not been confirmed (statistically significant estimate of parameter $\beta$ but positive sign). These observed differences and the formal results of the global Chow test lead to the conclusion that the parameters of these two regimes are highly heterogeneous. The Chow test applied to individual parameters leads to the same conclusion. Global spatial autocorrelation statistics for these two spatial regimes are shown in the lower part of Table 2 and at $1 \%$ significance level lead to the choice of SAR model. Following these findings, i.e. confirmed hypothesis of spatial heterogeneity - two spatial convergence regimes and also following global spatial autocorrelation statistics (Robust $L M(S A R)$ ), we proceed with extension of model (12) to spatial autocorrelation specification (see section 2.4). 
T a ble 2

The Estimation Results of Beta Convergence Model - Regimes without Spatial Autocorrelation

\begin{tabular}{|c|c|c|}
\hline & Regime 1 & Regime 2 \\
\hline $\begin{array}{l}\alpha \\
\beta\end{array}$ & $\begin{array}{r}3.4776^{* * *} \\
-0.3255^{* * * *}\end{array}$ & $\begin{array}{c}-0.6302 * \\
0.0815 * *\end{array}$ \\
\hline \multicolumn{3}{|c|}{$\begin{array}{c}\text { Regime variable: } z-\text { values of Getis-Ord statistics } \\
\text { Goodness of fit }\end{array}$} \\
\hline $\begin{array}{l}\mathrm{R}^{2} \\
\text { AIC } \\
\text { SC } \\
\text { Jarque-Bera } \\
\text { Breusch-Pagan }\end{array}$ & $\begin{array}{r}0.4103 \\
-52.949 \\
-48.210 \\
9.105^{* *} \\
4.432^{* *} \\
\end{array}$ & $\begin{array}{r}0.0349 \\
-302.458 \\
-296.234 \\
0.169 \\
0.293 \\
\end{array}$ \\
\hline \multicolumn{3}{|c|}{ Convergence characteristics' } \\
\hline $\begin{array}{l}\text { Speed of convergence } \\
\text { Half life }\end{array}$ & $\begin{array}{l}3.58 \% \\
19.36\end{array}$ & - \\
\hline \multicolumn{3}{|c|}{ Statistics of spatial autocorrelation } \\
\hline $\begin{array}{l}\text { LM }(S A R) \\
\text { Robust LM }(S A R) \\
\text { LM }(S E M) \\
\text { Robust LM }(\text { SEM })\end{array}$ & $\begin{array}{r}31.707 * * * \\
29.067 * * * \\
9.956 * * * \\
7.316 * * *\end{array}$ & $\begin{array}{c}11.541 * * * \\
15.214 * * * \\
15.214 * * * \\
0.673\end{array}$ \\
\hline \multicolumn{3}{|c|}{ Chow test } \\
\hline $\begin{array}{l}\alpha \\
\beta \\
\text { Global test }\end{array}$ & $\begin{array}{l}58.361 * * * \\
53.474 * * * \\
95.898 * * * \\
\end{array}$ & $\begin{array}{l}(0.0000) \\
(0.0000) \\
(0.0000) \\
\end{array}$ \\
\hline \multicolumn{3}{|c|}{ Statistics of global spatial autocorrelation } \\
\hline $\begin{array}{l}\text { LM }(S A R) \\
\text { Robust LM }(S A R) \\
\text { LM }(\text { SEM }) \\
\text { Robust LM }(\text { SEM })\end{array}$ & $\begin{array}{c}134.445 * * * \\
51.307 * * * \\
87.304 * * * \\
4.165 * *\end{array}$ & \\
\hline
\end{tabular}

Notes: Symbols ***, **, * indicate the rejection of $\mathrm{H}_{0}$ hypotheses at $1 \%, 5 \%$ and $10 \%$ level of significance, respectively, $p$ - values in parentheses. AIC - Akaike information criterion; $S C$ - Schwarz criterion; pseudo $\mathrm{R}^{2}$ (S) - spatial pseudo $\mathrm{R}^{2} ; \ln L$ - logarithm of $\log$ likelihood function; $A-K$ - Anselin-Kelejian; $L R$ - Likelihood Ratio; $L M$ - Lagrange Multiplier.

${ }^{1}$ Convergence characteristics are calculated only for regimes with statistically significant and negative parameter estimate of $\beta$ parameter.

Source: Own calculations.

\subsection{Income Club Convergence of the EU Regions in the Context of Spatial Autocorrelation}

Based on the results from the previous model, let us consider expanding the model (12) by a spatially lagged dependent variable (i.e., extending to the SAR regime model (7)). Instead of uniform spatial process we assume a more realistic assumption of separate spatial processes, which results in individual estimates of spatial autoregressive parameters. So we will start from the following modified version of the model (12): 


$$
\left[\begin{array}{l}
\mathbf{y}_{1} \\
\mathbf{y}_{2}
\end{array}\right]=\left[\begin{array}{cc}
\rho_{1} \mathbf{W}_{1} & \mathbf{0} \\
\mathbf{0} & \rho_{2} \mathbf{W}_{2}
\end{array}\right]\left[\begin{array}{l}
\mathbf{y}_{1} \\
\mathbf{y}_{2}
\end{array}\right]+\left[\begin{array}{cc}
\mathbf{X}_{1} & \mathbf{0} \\
\mathbf{0} & \mathbf{X}_{2}
\end{array}\right]\left[\begin{array}{l}
\gamma_{1} \\
\gamma_{2}
\end{array}\right]+\left[\begin{array}{l}
\mathbf{u}_{1} \\
\mathbf{u}_{2}
\end{array}\right]
$$

where, $\mathbf{W}_{1}$ and $\mathbf{W}_{2}$ are regime weight matrices, $\rho_{1}$ and $\rho_{2}$ are spatial autoregressive parameters of each spatial convergence club. For estimation of the model (13) we use again the estimator SML. The estimation results are presented in Table 3.

T a b le 3

The Estimation Results of Beta Convergence Model - Regimes with Spatial Autocorrelation

\begin{tabular}{|c|c|c|}
\hline & Regime 1 & Regime 2 \\
\hline $\begin{array}{l}\alpha \\
\beta \\
\rho\end{array}$ & $\begin{array}{r}1.0220 * * * \\
-0.0946 * * * \\
0.6816^{* * *} * \\
\end{array}$ & $\begin{array}{c}-0.4098 * \\
0.0457 * * \\
0.7235 * * * \\
\end{array}$ \\
\hline \multicolumn{3}{|c|}{$\begin{array}{l}\text { Regime variable: } z \text { - values of Getis-Ord statistics } \\
\text { Goodness of fit }\end{array}$} \\
\hline $\begin{array}{l}\text { pseudo } \mathrm{R}^{2} \\
\text { pseudo } \mathrm{R}^{2}(\mathrm{~S}) \\
\ln L \\
\text { AIC } \\
S C\end{array}$ & $\begin{array}{r}0.7275 \\
0.5797 \\
51.138 \\
-96.275 \\
-89.167 \\
\end{array}$ & $\begin{array}{r}0.6110 \\
0.1296 \\
207.808 \\
-409.616 \\
-400.280 \\
\end{array}$ \\
\hline \multicolumn{3}{|c|}{ Convergence characteristics $^{1}$} \\
\hline $\begin{array}{l}\text { Speed of convergence } \\
\text { Half life }\end{array}$ & $\begin{array}{l}0.90 \% \\
76.71 \\
\end{array}$ & - \\
\hline \multicolumn{3}{|c|}{ Chow test } \\
\hline $\begin{array}{l}\alpha \\
\beta \\
\rho \\
\text { Global test }\end{array}$ & $\begin{array}{c}13.297 * * * \\
12.458 * * * \\
0.248 \\
21.485 * * *\end{array}$ & $\begin{array}{l}(0.0003) \\
(0.0004) \\
(0.6182) \\
(0.0001)\end{array}$ \\
\hline
\end{tabular}

Notes: Symbols $* * *, * *, *$ indicate the rejection of $\mathrm{H}_{0}$ hypotheses at $1 \%, 5 \%$ and $10 \%$ level of significance, respectively, $p$ - values in parentheses. AIC - Akaike information criterion; $S C$ - Schwarz criterion; pseudo $\mathrm{R}^{2}$ (S) - spatial pseudo $\mathrm{R}^{2} ; \ln L$ - logarithm of log likelihood function

${ }^{1}$ Convergence characteristics are calculated only for regimes with statistically significant and negative parameter estimate of $\beta$ parameter.

Source: Own calculations.

Estimation of model (13) provided statistically significant estimates of convergence parameters, spatial autoregressive parameters for the first convergence club - economically ,weaker" regions. The convergence process within the regions of the second regime (economically ,stronger" regions) was not confirmed again due to the positive sign of the parameter $\beta$. These results are in line with the results of previous model (12). In comparison to model (12), we are experiencing a slower rate of convergence at $0.9 \%$ per year for the first regime regions. However, the results of non-spatial models such as model (12) must be interpreted with caution because they do not take into account spatial effects which produce unreliable estimators. Unlike the model (12), the model (13) already captures spatial interactions among regions and thus the conclusions provided by this model 
can be considered more reliable. Also, we can note that spatial autoregressive parameter $\rho$ for the first convergence club is highly positive and significant (see Table 3), meaning that the intensity of spatial interactions among these regions is quite high. This means, that for a region $i$, an increase of $1 \%$ of the spatially weighted average of the annual growth rate of its neighbouring regions will lead to an increase of the growth rate of region $i$ of $0.6816 \%$, once the effect of other variables is fixed.

Again, in accordance with the results of non-spatial regime model (12), observed differences and the formal results of the global Chow test of model (13), also led to the conclusion that the parameters of these two regimes are highly heterogeneous. But as far as spatial autoregressive parameter $\rho$, the results surprisingly indicate the adequacy of the assumption of a uniform spatial autoregressive process. Overall, model (12) and (13) showed that parameters are significantly different between spatial convergence regimes and thus spatial heterogeneity is present. But, model (13) indicates the adequacy of incorporation of the spatially lagged dependent variable into the income club convergence model since the spatial autoregressive parameter is indeed statistically significant. Our results therefore confirmed that the classical convergence clubs model (model (12)) is misspecified and the most appropriate model to model income convergence processes is model (13).

In the empirical literature, we can find several studies where the hypothesis of spatial club convergence of EU regions was confirmed (see section 1), but the conclusions are not entirely correct to compare due to many different assumptions (e.g. club determination, time span or spatial model specification). For example, the approach to determining clubs is different, Debarsy and Ertur (2006) also used ESDA tools as we did, but it is more common the division of regions on the basis of geographical characteristics (e.g. „West” and „East”) or division into so-called cohesive and non-cohesive countries, etc. However, in many cases (e.g. Fischer and Stirböck, 2004; Debarsy and Ertur, 2006 or Ramajo et al., 2005), the resulting number of clubs is two, which was also our conclusion. As far as convergence characteristics in other studies, we can often see that the convergence process within one of the clubs is not confirmed, which was also our case. On the other hand, the speed of convergence is often higher than we detected based on our model (13).

\section{Conclusion}

The origin and the development of spatial econometrics was influenced by the need to take into account spatial dependence, asymmetry in relations and mutual interaction of spatial units that are subject to econometric modelling. 
Nowadays, these motivational aspects persist as the economies of individual states, countries and regions are often interconnected and it is therefore necessary to take into account this existence of possible spatial dependence between the spatial units under consideration. This means that support for the development of one spatial unit, e.g. region can have a significant impact not only on the region, but also on geographically close regions. Consideration of spatial effects in econometric modelling causes problems with the use of the classical regression model and leads to the need to apply spatial econometric techniques and spatial statistics. The omission of spatial dependence in econometric modelling causes problems with the consistency and efficiency of parameter estimates, and consequently such estimates lead to misleading conclusions. The reason for using the apparatus of spatial econometrics is evident also in the context of the EU countries/regions because the economies of individual EU member states are largely interconnected and thus the development of selected modelled indicators in a specific region interacts with the development of the indicator in geographically close regions. The EU regional policy is aimed at the gradual elimination of regional disparities, especially in the areas of economic growth, education, research and innovation, employment, social inclusion and poverty reduction, which were also declared by strategic document Europe 2020 (European Commission, 2012). Taking into account spatial multiplier effects allows more efficient decision-making and allocation of financial resources in order to eliminate regional disparities, as taking concrete steps and adopting specific laws in a country will also affect events in other, possibly in all EU countries.

The empirical analysis presented in this paper focused on testing the spatial income convergence hypothesis of the 245 NUTS 2 EU regions during the period 2003 - 2014. The first part of the analysis was aimed at the analysis of spatial autocorrelation on a sample of all 245 regions and we found that the rate of economic growth in the region is not only affected by the exogenous characteristics of the region, but also potentially by the rate of economic growth, economic in neighbouring regions through a spatial multiplier.

In the next part of the empirical analysis we focused on another spatial effect, namely spatial heterogeneity and based on the analysis of the results of estimates of models (12) and (13) the hypothesis of two spatial convergence clubs can be considered as confirmed. However, a statistically significant but positive estimate of the parameter $\beta$ does not indicate a process of convergence of economically „stronger" regions, i.e. regions of Regime 2. The statistical significance of the spatial autoregressive parameter $\rho$ indicates the adequacy of incorporation of the spatially lagged dependent variable into the income convergence model, but the results surprisingly indicate the adequacy of the assumption of a uniform spatial autoregressive process while heterogeneity of other regression parameters. 
Our analysis points to the eligibility of applying spatial econometric tools within the frame of modelling convergence processes. Of course, our analysis is not exhaustive and several intuitive extensions of the analysis are evident. The whole analysis was carried out based only on the first-order queen case neighbourhood matrix and based on this matrix through the Getis-Ord local statistics the convergence clubs were determined. Therefore, it would be useful to examine the sensitivity of the results to change the matrix of spatial weights as a change of a regime variable.

\section{References}

ABREU, M. - De GROOT, H. (2005): Space and Growth: A Survey of empirical Evidence and Methods. Région et Dévelopment, 21, pp. 13 - 44.

ANSELIN, L. (1988): Spatial Econometrics: Methods and Models. Dordrecht: Kluwer Publisher. 284 p. ISBN 978-94-015-7799-1.

ANSELIN, L. - REY, S. J. (2014): Modern Spatial Econometrics in Practice: A Guide to GeoDa, GeoDaSpace and PySAL. Chicago: GeoDa Press LLC. 394 p. ISBN-13:978-0986342103.

ARBIA, G. (2006): Spatial Econometrics. Statistical Foundations and Applications to Regional Convergence. Berlin Heidelberg: Springer-Verlag. 207 p. ISBN-10 3-540-32304-X.

BARRO, R. J. - SALA-I-MARTIN, X. (1990): Government Spending in a Simple Model of Endogenous Growth. The Journal of Political Economy, 98, No. 5, pp. $103-125$.

BARRO, R. J. - SALA-I-MARTIN, X. (1991): Convergence across States and Regions. Brookings Papers on Economic Activity, 22, No. 1, pp. 107 - 182.

BARRO, R. J. - SALA-I-MARTIN, X. (1992): Convergence. Journal of Political Economy, 100, No. 2, pp. $223-251$.

BARRO, R. J. - SALA-I-MARTIN, X. (2004): Economic Growth. Second Edition. New York: McGraw-Hill. 539 p. ISBN 0-262-02553-1.

BATTISTI, M. - Di VAIO, G. (2009): A Spatially Filtered Mixture of $\beta$-convergence Regressions for EU Regions, 1980 - 2002. In: ARBIA, G. and BALTAGI, B. H. (ed.): Spatial Econometrics. Methods and Applications. Heidelberg: Physica-Verlag, pp. 105 - 121. ISBN 978-3-7908-2069.

BAUMONT, C. - ERTUR, C. - LE GALLO, J. (2001): A Spatial Econometric Analysis of Geographic Spillovers and Growth for European Regions, 1980 - 1995. [Cit. 2017-08-29.] Available at: 〈http://leg.u-bourgogne.fr/documents-de-travail/e2001-04.pdf〉.

BRUNSDON, C. - FOTHERINGHAM, A. S. - CHARLTON, M. (1999): Some Notes on Parametric Significance Tests for Geographically Weighted Regression. Journal of Regional Science, 39, No. 3, pp. $497-524$.

CARRINGTON, A. (2003): A Divided Europe? Regional Convergence and Neighbourhood Effects. Kyklos, 56, No. 3, pp. $381-393$.

CHOCHOLATÁ, M. (2018): Spatial Analysis of the Tertiary Educational Attainment in European Union. In: Proceedings of the 15th International Conference Efficiency and Responsibility in Education. Praha, pp. $117-124$.

DALL'ERBA, S. (2005): Productivity Convergence and Spatial Dependence among Spanish Regions. Journal of Geographical Systems, 7, No. 2, pp. 207 - 227.

DEBARSY, N. - ERTUR, C. (2006): The European Enlargement Process and Regional Convergence Revisited: Spatial Effects Still Matter. [Cit. 2017-08-29.] Available at: 〈http://www-sre.wu-wien.ac.at/ersa/ersaconfs/ersa06/papers/198.pdf>.

DURLAUF, S. N. - JOHNSON, P. A. (1995): Multiple Regimes and Cross-country Growth Behaviour. Journal of Applied Econometrics, 10, No. 4, pp. 365 - 384. 
ERTUR, C. - Le GALlO, J. - BAUMONT, C. (2006): The European Regional Convergence Process, 1980 - 1995: Do Spatial Regimes and Spatial Dependence Matter? International Regional Science Review, 29, No. 1, pp. 3 - 34 .

EUROPEAN COMMISSION (2012): Consolidated versions of the Treaty on European Union and the Treaty on the Functioning of the European Union. Official Journal of the European Union, 55, No. C326, pp. 1 - 390. [Cit. 2015-05-02.] Available at: <http://eur-lex.europa.eu/LexUriServ/LexUriServ.do?uri=OJ:C:2012:326:FULL:EN:PDF>.

EUROSTAT (2018a): Regional Eurostat Statistics Database. [Cit. 2018-05-02.] Available at: $<$ https://ec.europa.eu/eurostat/web/regions/data/database>.

EUROSTAT (2018b): Geographical Information and Maps. [Cit. 2018-05-02.] Available at: $<$ https://ec.europa.eu/eurostat/web/gisco/geodata/reference-data/administrative-unitsstatistical-units/nuts>.

FELDKIRCHER, M. (2006): Regional Convergence within the EU-25: A Spatial Econometric Analysis. In: Proceedings of OeNB Workshops „New Regional Economics in Central European Economies: The Future of CENTROPE”, No. 9, pp. $101-119$.

FINGLETON, B. - LÓPEZ-BAZO, E. (2006): Empirical Growth Models with Spatial Effects. Papers in Regional Science, 85, No. 2, pp. 177 - 198.

FISCHER, M. M. - STIRBÖCK, C. (2004): Regional Income Convergence in the Enlarged Europe, 1995 - 2000: A Spatial Econometric Perspective. [Discussion Paper.] Mannheim: Centre for European Economic Research (ZEW). [Cit. 2015-16-09.] Available at: $<\mathrm{ftp}: / / \mathrm{ftp}$. zew.de/pub/zew-docs/dp/dp0442.pdf $>$.

FURKOVÁ, A. - CHOCHOLATÁ, M. (2016): Spatial Econometric Modelling of Regional Club Convergence in the European Union. Ekonomický časopis/Journal of Economics, 64, No. 4, pp. $367-386$.

GALOR, O. (1996): Convergence? Inferences from Theoretical Models. The Economic Journal, 106, No. 437, pp. $1056-1069$.

GIBBONS, S. - OVERMAN, H. G. (2012): Mostly Pointless Spatial Econometrics? Journal of Regional Science, 52, No. 2, pp. $172-191$.

HANČLOVÁ, J. et al. (2010): Makroekonometrické modelování České ekonomiky a vybraných ekonomik EU. Ostrava: VŠB-TU Ostrava. 310 p. ISBN 978-80-248-2353-9.

KELEJIAN, H. H. - PRUCHA, I. R. (1998): A Generalized Spatial Two Stage Least Squares Procedure for Estimating a Spatial Autoregressive Model with Autoregressive Disturbances. Journal of Real Estate Finance and Economics, 17, No. 1, pp. 99 - 121.

KRUGMAN, P. (1991): Increasing Returns and Economic Geography. Journal of Political Economy, 99, No. 3, pp. $483-499$.

LeSAGE, J. - PACE, K. (2009): Introduction to Spatial Econometrics. Boca Raton: Chapman and Hall/CRC. 374 p. ISBN 81420064247.

MANKIW, N. G. - ROMER, D. - WEIL, D. N. (1992): A Contribution to the Empirics of Economic Growth. Quarterly Journal of Economics, 107, pp. 407-437.

MORA, T. (2005): Evidencing European Regional Convergence Clubs with Optimal Grouping Criteria. Applied Economics Letters, 12, No. 15, pp. 937 - 940.

PAAS, T. et al. (2007): Econometric Analysis of Income Convergence in Selected EU Countries and Their NUTS 3 Level Regions. SSRN Electronic Journal. [Cit. 2017-08-29.] Available at: <http://papers.ssrn.com/sol3/papers.cfm?abstract_id=1078863>.

PAAS, T. - SCHLITTE, F. (2009): Spatial Effects of Regional Income Disparities and Growth in the EU Countries and Regions. [Cit. 2017-08-29.] Available at: <http://ec.europa.eu/eurostat/documents/1001617/4398377/S3P2-SPATIAL-EFFECTS-TIIUPAAS-FRISO-SCHLITTE.pdf>.

PAN. X. - LIU, Q. - PENG, X. (2015): Spatial Club Convergence of Regional Energy Efficiency in China. Ecological Indicators, 51, pp. $25-30$. 
PAPALIA, B. - BETARELLI, S. (2012): Identification and Estimation of Club Convergence Models with Spatial Dependence. International Journal of Urban and Regional Research, 37, No. 6, pp. $2094-2115$.

QIN, C. - YE, X. - LIU, Y. (2017): Spatial Club Convergence of Regional Economic Growth in Inland China. In Sustainability, 9, No. 7, pp. 1189 - 1203.

RAMAJO, J. et al. (2005): Spatial Heterogeneity and Interregional Spillovers in EU: Some Evidence about the Effects of Cohesions Policies on Convergence. The Regional Economics Applications Laboratory. [Discussion Paper Series.] [Cit. 2017-08-29.] Available at: <http://www.real.illinois.edu/d-paper/05/05-t-2.pdf>.

RAMAJO, J. et al. (2008): Spatial Heterogeneity and Interregional Spillovers in the European Union: Do Cohesion Policies Encourage Convergence across Regions? European Economic Review, 52, No. 3, pp. $551-567$.

REY, S. J. - MONTOURI, B. D. (1999): US Regional Income Convergence: A Spatial Econometric Perspective. Regional Studies, 33, No. 2, pp. $143-156$.

ROMER, P. M. (1986): Increasing Return and Long-Run Growth. Journal of Political Economy, 94, No. 5, pp. $1002-1037$.

SOLOW, R. A. (1956): A Contribution to the Theory of Economic Growth. The Quarterly Journal of Economics, 70, No. 1, pp. $65-94$. 